\title{
GRUPO DE CESSAÇÃO DO TABAGISMO: UM RELATO DE EXPERIÊNCIA
}

\author{
Eduarda Nichele \\ Nutricionista, Universidade do Extremo Sul Catarinense, \\ dudanichele@gmail.com \\ Mônica Martins Binatti \\ Profissional de Educação Física, Universidade do Extremo Sul Catarinense, \\ monicabinatti@hotmail.com \\ Vera Lúcia Vicencia \\ Serviço Social, Prefeitura Municipal de Criciúma, \\ vlv456@hotmail.com \\ Cristiane Duarte Daminelli \\ Psicóloga, Prefeitura Municipal de Criciúma, \\ psidaminelli@gmail.com \\ Taise Rocha Macedo \\ Mestra, Prefeitura Municipal de Criciúma, \\ taiserm@hotmail.com \\ Rita Suselaine Vieira Ribeiro \\ Mestra, Universidade do Extremo Sul Catarinense, \\ rsv@unesc.net
}

\section{RESUMO}

O tabagismo é um tipo de transtorno mental e comportamental por consequência ao uso de substâncias psicoativas, como a nicotina presente no tabaco, que causa a dependência física, psicológica e comportamental. Além dis- 
so, é considerado o maior motivo isolado que se pode evitar de enfermidades e óbitos precoces em todo o mundo. A partir de 2005, o tratamento formal para cessação do tabagismo passou a ser implantado em unidades de saúde do Sistema Único de Saúde (SUS), de forma planejada e monitorada. Dentre as iniciativas brasileiras elaboradas para responder ao desafio das doenças crônicas, o controle do tabagismo é responsável por grande parte da diminuição das doenças crônicas não transmissíveis. Dessa forma, podemos citar o Grupo de Cessação do Tabagismo de uma regional de saúde, localizada no município de Criciúma (SC), organizado por uma equipe multiprofissional, com apoio da Coordenação Municipal de Combate ao Tabagismo (Secretaria do Municipal de Saúde). O objetivo deste programa é ajudar os participantes a deixarem de fumar, fornecendo-lhes todas as informaçóes e estratégias necessárias para direcionar seus próprios esforços nesse sentido, incentivando-os a aplicar o que aprenderam com o programa em outros aspectos da sua vida. O paciente tabagista pode procurar o programa por vontade própria ou por encaminhamento de algum profissional da saúde, onde são passadas todas as informaçóes e esclarecimentos iniciais. É feito uma triagem para coletar informaçóes, como, por exemplo, dados pessoais, familiares, história tabágica, grau de dependência à nicotina, motivação para parar de fumar, entre outras. Em seguida, o paciente é encaminhado ao grupo, são grupos de 10 a 15 pessoas, com sessóes de 1 hora e meia. A equipe multiprofissional envolvida é composta por enfermeira, assistente social, psicóloga, profissional de educação física e nutricionista. Os grupos possuem assuntos variados e sequenciados e utilizam apostilas fornecidas pelo Ministério da Saúde. Com base nisso, observamos que o grupo de controle do tabagismo foi muito importante para os participantes, motivando, ouvindo e auxiliando-os, além de promover educação em saúde, em todas as etapas do programa.

Palavras-chave: Tabagismo; Educação em Saúde; Equipe Multiprofissional. 